\title{
Treatment of C1.1 (AO-41) tibial plateau fracture: A finite element analysis of single medial, lateral and dual plating
}

\author{
NORIN FORNA ${ }^{1}$, FLORIN MUNTEANU ${ }^{2}$, SÎNZIANA ANCA BUTNARU MOLDOVEANU ${ }^{2}$, \\ LILIANA SAVIN $^{1 *}$, PAUL DAN SÎRBU $^{1 *}$ and BOGDAN PUHA ${ }^{1 *}$ \\ ${ }^{1}$ Department of Surgery II, Faculty of Medicine, 'Grigore T. Popa' University of Medicine and \\ Pharmacy, 700115 Iasi; ${ }^{2}$ Department of Biomedical Sciences, Faculty of Medical Bioengineering, \\ 'Grigore T. Popa' University of Medicine and Pharmacy, 700454 Iasi, Romania
}

Received September 24, 2021; Accepted October 26, 2021

DOI: $10.3892 /$ etm.2022.11121

\begin{abstract}
Bicondylar tibial plateau fractures pose many challenges in surgical treatment. The aim of the present study was to analyze three methods of reduction, single medial, single lateral, and dual plating, for the treatment of a bicondylar tibial plateau fracture, through finite element analysis (FEA). A simple metaphyseal fracture, type $\mathrm{C} 1.1$ (AO-41) was modeled on a CT-derived 3D model of the knee. Lateral and medial proximal tibial polyaxial plates with screws were modeled and placed accordingly for the three methods of reduction. Simulation of physiological type loading corresponding to the maximal weight acceptance phase during a slow walking gait cycle was performed using FEA. Values of stress and strain were recorded near the fracture lines. Dual plating provided a decrease of stress and strain in the tibial plateau area. However, the differences in the values among the three cases were small. The stress concentration areas were located in the vicinity of the fracture, predominantly in the area of the tibial plateau. Considering the limitations of the present study, the results revealed that dual plating leads to smaller stress and strain values near the fracture lines in the tibial plateau area. However, values obtained for single lateral plating are close in range. Considering the complexity of the surgical approach for dual plating, single lateral plating may be a solution for good reduction with fewer surgical risks and complications. Further studies on the $\mathrm{C} 1.1$ fracture (AO-41) are needed to analyze
\end{abstract}

Correspondence to: Professor Florin Munteanu or Mrs. Sînziana Anca Butnaru Moldoveanu, Department of Biomedical Sciences, Faculty of Medical Bioengineering, 'Grigore T. Popa' University of Medicine and Pharmacy, 9-13 M. Kogalniceanu Str., 700454 Iasi, Romania

E-mail: flmunteanu@yahoo.com

E-mail: sanziana_moldoveanu@yahoo.com

${ }^{*}$ Contributed equally

Key words: tibial plateau, fracture reduction, stabilization, dual plating, lateral plating, finite element analysis the complex issue of reducing and stabilizing such a fracture and to characterize the postoperative state while providing predictable parameters for an optimal result.

\section{Introduction}

Bicondylar tibial plateau fractures are common injuries of the lower limb, leading to the destabilization of both the medial and lateral condyles (1-3). This type of fracture accounts for up to $39 \%$ of all tibial plateau fractures (4). The bicondylar fracture occurs as a result of significant trauma involving a high-energy mechanism in which the varus or valgus is combined with axial loading (3).

The C1.1 (AO-41) fracture, from the AO/OTA classification, is a complex variation of bicondylar fractures where the fracture line is described as having an inverted ' $\mathrm{Y}$ ' trajectory (5). In the case of a bicondylar fracture, the reduction and fixation techniques usually involve an open reduction and an internal fixation using a plate and screws that can be applied laterally, medially, or combined (4). Dual plating is considered the most stable type of fixation for bicondylar tibial plateau fractures. However, the surgical approach for dual plating is complex, involving two incisions and soft-tissue manipulation. Moreover, for this type of fracture, soft-tissue complications are an important concern associated with dual plating (4). Plates with polyaxial stability (PAS) offer the possibility to adapt the position of the screws to the fracture trajectory. Due to this, appropriate fixation and stabilization can be achieved through a single plate with lateral fixation (6).

However, each case of bicondylar fracture must be analyzed in the context of specific clinical features, considering the trajectory of the fracture and the affected soft tissues. This is necessary because no single method can guarantee optimal results for the full range of possible clinical cases (4). The selection of an inappropriate treatment for the bicondylar fracture can lead to a reduction in the range of motion of the joint and joint instability. There are, of course, several other issues that contribute to poor results in the treatment of bicondylar plateau fractures. The advanced age of $>50$ years of a patient has been associated with poor postoperative results (7-9). Smoking, the existence of an open fracture, and compartment syndrome can increase the risk of infection $(10,11)$. In assessing 
the outcome of a fracture at the knee joint, the Rasmussen and Iowa scores are the only tools specifically designed for this $(12,13)$. However, these tools have not been validated with a rigorous methodology to assess the results of patients with bicondylar tibial plateau fractures (4).

The finite element analysis (FEA) method is particularly advantageous as it allows for the virtual reconstruction of the anatomical and physiological conditions of this type of fracture. Bone shape and fracture trajectory, as well as biomechanical conditions, such as the force generated by muscle deformation, which in turn is transmitted through tendons to the bone, can be simulated (14).

It is quite difficult to make an experimental device, in vitro, that respects the anatomical and physiological conditions as can be done in FEA. This method has been widely used in trauma research in orthopedics, to determine whether there are stress concentrators in the implants or osteosynthesis used, that would lead to their deformation or rupture, but also to analyze the effect of these devices on the bone tissue (14-16). For the C1.1 type bicondylar fracture (AO-41), the scientific literature presents a lack of FEA studies to distinguish between different simulated scenarios and to analyze the results obtained.

The aim of the present study was to analyze three methods of reduction, single medial, single lateral and dual plating, for the treatment of the bicondylar tibial plateau fracture, C1.1 (AO-41), using FEA to determine the stress and strains at the level of the reduced and stabilized fracture.

\section{Materials and methods}

Knee model. For this study, a 3D model of the knee was obtained using CT images in Slicer3D (http://www.slicer. org) and 3D modeling with further processing was carried out using Autodesk ReCap Photo version 2019 and Autodesk Fusion360 (Autodesk, Inc.). Following the bone reconstruction, the menisci and cartilage tissue were modeled in Autodesk Fusion360 (Autodesk, Inc.) (Fig. 1).

Method selection and load simulation. A simple metaphyseal fracture, type C1.1 (AO-41), according to the AO/OTA classification, was modeled, with an inverted ' $Y$ ' trajectory. For this type of fracture, three methods of fracture reduction were selected, single medial, single lateral and dual plating. Proximal polyaxial tibial plates and screws of $3 \mathrm{~mm}$ diameter, with no threads were modeled and placed accordingly for the three methods of reduction. To ensure contact areas between the plate and tibia, very small volumes of material were cut from the plates, following the contour of the contact surfaces. These volumes were very small and negligible in terms of plate thickness, having only the role of providing small contact areas. The positioning of the plates and screws on the fractured 3D model is presented in Fig. 2.

Load simulation was performed in the Simulation Mechanical 2017 software (Autodesk, Inc.). Materials assigned to all parts were considered materials with linear isotropic and elastic mechanical properties and were characterized by Young's modulus and the Poisson's ratio, the values of which are presented in Table I (17-19).

Determining the magnitude of the forces. To obtain the appropriate magnitude of the forces applied, the peak value in the maximal weight acceptance phase that occurs during a slow walking gait cycle was considered. In a complete gait cycle, the reaction force has two peaks occurring at weight acceptance and push-off, as well as a minimum value in mid-stance. The first peak was considered for the calculation of the applied forces. The approximation of the position, as a percentage of the gait cycle, of this first peak was produced based on the data reported by Arnold and his collaborators (20). Thus, the first peak of the ground reaction force occurs at $16 \%$ of the gait cycle at a walking speed of $1 \mathrm{~m} / \mathrm{sec}$.

The forces were calculated for an individual with a body mass of $70 \mathrm{~kg}$. The applied loads were represented by the forces of the quadriceps muscle $\left(\mathrm{F}_{\mathrm{Q}}\right)$, semitendinosus $\left(\mathrm{F}_{\mathrm{St}}\right)$ and semimembranosus $\left(\mathrm{F}_{\mathrm{Sm}}\right)$, medial and lateral gastrocnemius $\left(\mathrm{F}_{\mathrm{Gm}}, \mathrm{F}_{\mathrm{Gl}}\right)$, biceps femoris $\left(\mathrm{F}_{\mathrm{Bf}}\right)$, as well as the ground reaction force $(\mathrm{GRF})$, as revealed in Fig. 3.

The magnitude of these forces was calculated using the formula:

$$
\mathrm{Fm}=\mathrm{Ts} \times \mathrm{PCSA} \times \mathrm{V}_{\mathrm{EMG}}
$$

where Fm is muscle force, Ts is specific tension, PCSA is physiological cross-sectional area, and $\mathrm{V}_{\mathrm{EMG}}$ is normalized value of muscle activity during maximal weight acceptance.

For the specific tension of the muscle, an average value of $22.5 \mathrm{~N} / \mathrm{cm}^{2}$ was used, and the physiological cross-sectional area, specific to each muscle, was selected from available data from the literature $(21,22)$. The normalized value of the muscle activity, during maximal weight acceptance, was approximated from the data reported by Arnold and his collaborators (20).

The directions of the muscle forces were established according to data from the literature (22-26). In the frontal plane, an angle of $3^{\circ}$ between the mechanical and the vertical axis was considered. In the simulation interface, the directions of the forces were set to the vertical axis. In the frontal plane, $\mathrm{F}_{\mathrm{Q}}$ was oriented in the direction of the $\mathrm{Q}$ angle $\left(14^{\circ}\right)$, calculated to the vertical axis, $\mathrm{F}_{\mathrm{Bf}} 11.8^{\circ}$ medial, $\mathrm{F}_{\mathrm{Sm}} 7^{\circ}$ lateral, $\mathrm{F}_{\mathrm{St}} 5.1^{\circ}$ lateral, $\mathrm{F}_{\mathrm{Gl}} 4.8^{\circ}$ lateral, and $\mathrm{F}_{\mathrm{Gm}} 5.3^{\circ}$ medial to the mechanical axis of the tibia (23-27).

For the sagittal plane, the knee was considered to be in extension, and the anatomical axis of the tibia, which corresponded to the mechanical axis, was vertical. In the sagittal plane, $\mathrm{F}_{\mathrm{Q}}, \mathrm{F}_{\mathrm{Gl}}$, and $\mathrm{F}_{\mathrm{Gm}}$ were considered parallel to the tibial axis and $\mathrm{F}_{\mathrm{Bf}} 7.3^{\circ}$ anterior to the tibial axis, $\mathrm{F}_{\mathrm{Sm}}$ oriented at $16.1^{\circ}$ and $\mathrm{F}_{\mathrm{St}}$ at $19.6^{\circ}$ posterior to the tibial axis (24-26).

Regarding the direction of the GRF, the step size was extremely small postoperatively. Thus, GRF acted normally on the tibial surface, the angle between the tibia and the reaction force being negligible. The magnitude of the GRF was approximated based on data reported by Arnold and his collaborators, at maximum weight acceptance (20). Table II reveals the rounded values of the muscular forces as well as the GRF. The fibula bone was not included in this study. However, the contact area between the fibula and the tibia was considered as the area of application of the force developed by the biceps femoris muscle, which has its insertion in the fibula. Constraints were applied to the diaphyseal surface of the femur, completely restricting the movement of this surface. The type of contact selected between the simulation elements was bonded. A descriptive image of the forces and constraints applied to the 3D model is shown in Fig. 3. 
A

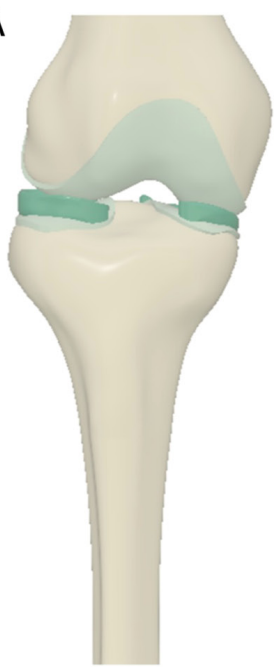

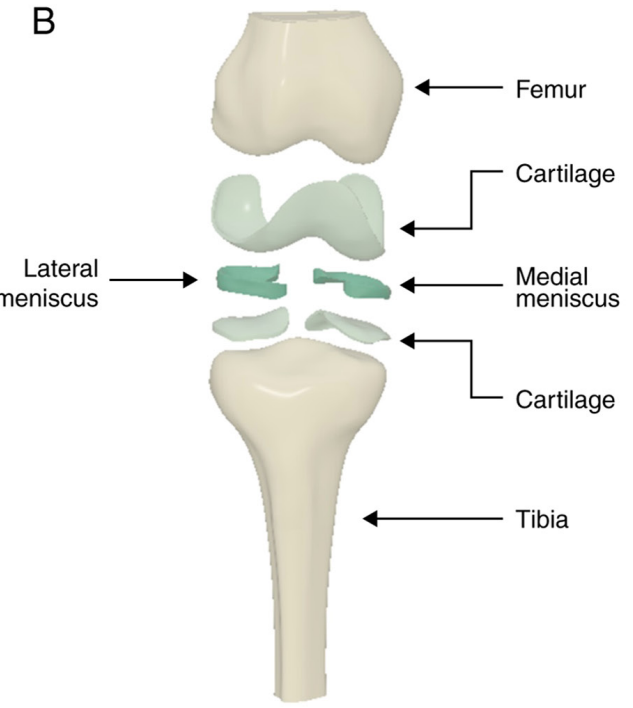

C

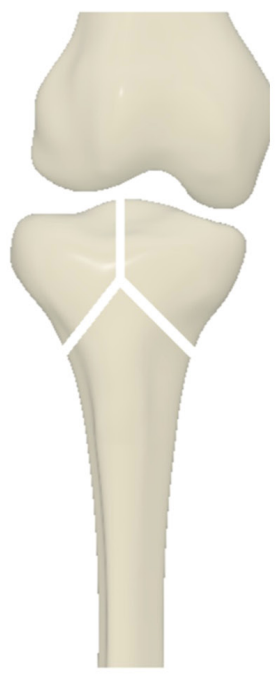

Figure 1. A 3D model of the knee. (A) Frontal view of the knee model. (B) Exploded view of the knee model. (C) Modeled C1.1 (AO-41) fracture.

A
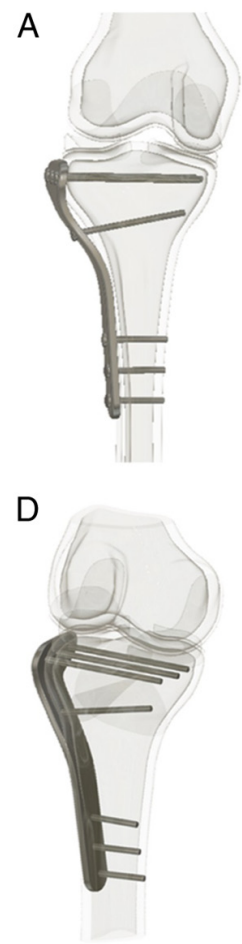

$\mathrm{B}$

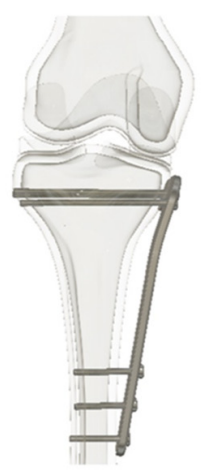

$\mathrm{E}$

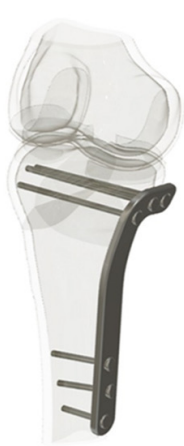

C

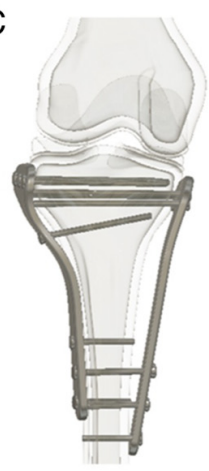

$\mathrm{F}$

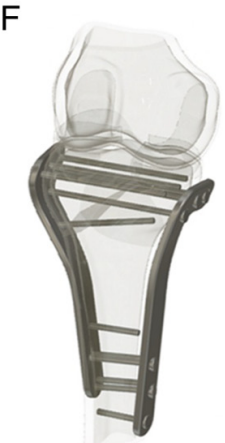

Figure 2. Positioning of the plates and screws on the modeled fracture for the three methods of reduction selected. Frontal plane view of (A) single lateral plating, (B) single medial plating, (C) dual plating. Medial descriptive view of (D) single lateral plating, (E) single medial plating, (F) dual plating.

\section{Results}

Analysis of maximum principal stress and strain values. In this study, the values of maximum principal stress and strain were analyzed (Figs. 4 and 5). Values were recorded at the cortical level near the fracture lines, in two areas, the central frontal area (where the fracture lines split) and the tibial plateau area. To eliminate artifacts represented by high local values, an average of 3 values recorded in the vicinity of the area of interest was made. The highest stress and strain values

were recorded near the fracture lines, in the tibial plateau area. Dual plating led to a decrease of stress and strain values in this region. In the center frontal area, values were similar between the three methods of reduction analyzed.

Stress distribution. The distribution of the stress values at the level of the tibia was also analyzed. For an optimal view of the stress distribution, the color legend was changed to highlight the areas of stress concentration. Thus, the upper-stress limit for this stress distribution was selected as $10 \mathrm{MPa}$. This value does not represent the maximum stress obtained but is only a value selected for a stronger exposure of the high-stress concentration areas. The stress concentration areas were located in the region of the fracture, predominantly in the area of the tibial plateau, as is evident in Figs. 6-8. Small areas of stress concentration were evident in regions where the forces were applied and the plates came in direct contact with the bone. These areas appear in all three cases due to the same loading applied.

\section{Discussion}

The aim of the present study was to analyze the complex reduction and fixation of the tibial plateau C1.1 (AO-41) type fracture, considering three methods of reduction, single medial, single lateral and dual, by using proximal polyaxial plates and screws. The results revealed that both stress and strain increased in the region of the tibial plateau. The stresses and strains increased due to the forces applied but also the fixture of the plates. The bone discontinuity caused by the fracture path caused a large amount of stress on the plate when loading was applied, which was then transmitted to the bone tissue near the screws and further along to the fracture lines.

Strain values can be analyzed in relation to the physiological intervals defined by Frost through the mechanostat theory (28). The theory defines the mechanism of adaptation of the bone tissue to the action of a mechanical stimulus that is maintained in a specific area by the variation of bone mass $(29,30)$. In other words, the action of a mechanical stimulus leads to a 
Table I. Material properties.

\begin{tabular}{|c|c|c|}
\hline Material (Refs.) & $\begin{array}{c}\text { Young's } \\
\text { Modulus (MPa) }\end{array}$ & Poisson's ratio \\
\hline Cortical bone (17) & 17,000 & 0.33 \\
\hline Trabecular bone (17) & 5,000 & 0.33 \\
\hline Cartilage (18) & 5 & 0.46 \\
\hline Menisci (18) & 59 & 0.49 \\
\hline Titanium (19) & 110,000 & 0.3 \\
\hline
\end{tabular}

A

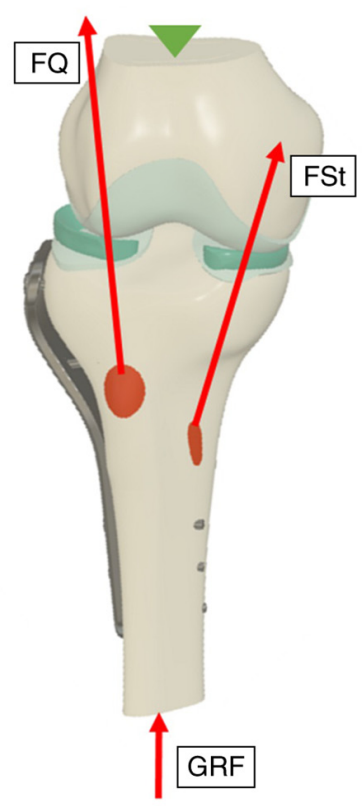

$\mathrm{B}$

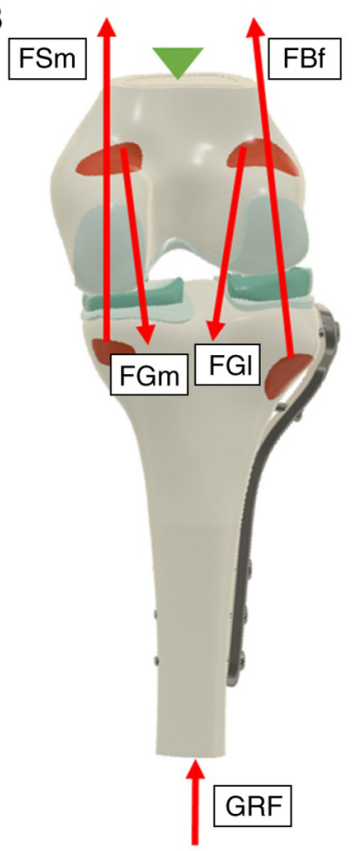

Figure 3. Descriptive image of forces and constraints applied to the 3D model. (A) Anterior and (B) posterior view. $\mathrm{F}_{\mathrm{Q}}$, quadriceps muscle; $\mathrm{F}_{\mathrm{St}}$, semitendinosus; $\mathrm{F}_{\mathrm{Sm}}$, semimembranosus; $\mathrm{F}_{\mathrm{Gm}}$, medial gastrocnemius; $\mathrm{F}_{\mathrm{Gl}}$, lateral gastrocnemius; $\mathrm{F}_{\mathrm{Bf}}$, biceps femoris; GRF, ground reaction force.

remodeling of the bone tissue, for the bone to respond favorably to the applied loads. The response of bone tissue can be quantified by analyzing the values of the strain generated $(28,31)$. There are four intervals of bone strain, $<1,000 \mu \varepsilon$ (absence of an applied load, potential for tissue atrophy), 1,000-1,500 $\mu \varepsilon$ (tissue homeostasis), 1,500-3,000 $\mu \varepsilon$ (physiological load that promotes bone remodeling), and $>3,000 \mu \varepsilon$ (overload associated with fractures and bone resorption) $(28,31)$.

The values of strain obtained in both areas were found in the minimum strain range. Although it is considered that in the present study the strain was not enough to achieve bone remodeling, it is noteworthy that the simulation was performed taking into account forces applied during a smaller walking speed. However, the average speed for normal walking is reported at approximately $1.33 \mathrm{~m} / \mathrm{sec}$, while slow walking speed is approximately $0.66 \mathrm{~m} / \mathrm{sec}$ (32). By decreasing the walking speed, the muscle forces also decrease, resulting in lower values of stress and strain. At lower speeds, acceleration is also smaller. The same acceleration can be transposed to the system of forces in the human body, i.e., the lower the
Table II. Rounded values of applied forces (N).

\begin{tabular}{lcccccc}
\hline $\mathrm{F}_{\mathrm{Q}}$ & $\mathrm{F}_{\mathrm{Sm}}$ & $\mathrm{F}_{\mathrm{St}}$ & $\mathrm{F}_{\mathrm{Bf}}$ & $\mathrm{F}_{\mathrm{Gl}}$ & $\mathrm{F}_{\mathrm{Gm}}$ & $\mathrm{GRF}$ \\
\hline 213 & 50 & 13 & 42 & 24 & 62 & 720
\end{tabular}

$\mathrm{F}_{\mathrm{Q}}$, quadriceps muscle; $\mathrm{F}_{\mathrm{St}}$, semitendinosus; $\mathrm{F}_{\mathrm{Sm}}$, semimembranosus; $\mathrm{F}_{\mathrm{Gm}}$, medial gastrocnemius; $\mathrm{F}_{\mathrm{Gl}}$, lateral gastrocnemius; $\mathrm{F}_{\mathrm{Bf}}$, biceps femoris; GRF, ground reaction force.

acceleration, the lower the forces exerted by the muscles, and thus, the stress transmitted to the bone tissue becomes smaller. In addition, the variation of the GRF in a complete walking cycle may change and in the context of a fracture, the variation can also extend to the walking phases. As the speed of movement or the angle of the GRF changes by increasing the step size, the load on the tibia may increase accordingly.

The variation obtained shows that dual plating leads to smaller stress and strain values near the fracture lines in the tibial plateau area. Dual plating is considered to be the most stable type of fixation for bicondylar tibial plateau fractures; however, the surgical approach involved is complex and soft-tissue complications are an important concern associated with dual plating (4). In the present study, values obtained for single lateral plating were close in range. Considering the complexity of the surgical approach for dual plating, single lateral plating may be a solution for good reduction with fewer surgical risks and complications.

Moreover, plates with PAS provide the means to adapt the position of the screws to the fracture trajectory. Thus, appropriate fixation and stabilization can be achieved through a single plate with lateral fixation (6).

We observed that the stress concentration areas are located in the fracture area, more specifically in the tibial plateau region, in the vicinity of the fracture line. The location of the stress concentration areas may derive from the loading generated by the muscular forces and also the type of contact between the surfaces. The type of contact between the elements is a limitation of FEA studies as it is difficult to characterize the contact between the fracture fragments, postoperatively.

For this type of fracture, there is a lack of FEA studies to help distinguish between different simulated scenarios and to analyze the results obtained. As aforementioned, the existing studies describe only from a clinical point of view, the impact of different methods of reduction and osteosynthesis of simple metaphyseal fracture of the tibial plateau.

The FEA study by Samsami et al addresses the bicondylar tibial plateau fracture; however, the fracture trajectory is extremely different from that of the present study (33). Additionally, the loading mode differs, forces of $350 \mathrm{~N}$ and $250 \mathrm{~N}$ were applied to the tibial plateau region in that study (33).

Being a type of fracture characterized by increased heterogeneity from patient to patient, it also has a high risk of complications of treatment (34). Among the reported complications, there are associated lesions of the menisci and cruciate ligaments, vascular or nerve lesions, vicious consolidation, knee stiffness, and osteoarthritis (4). The heterogeneity of the 


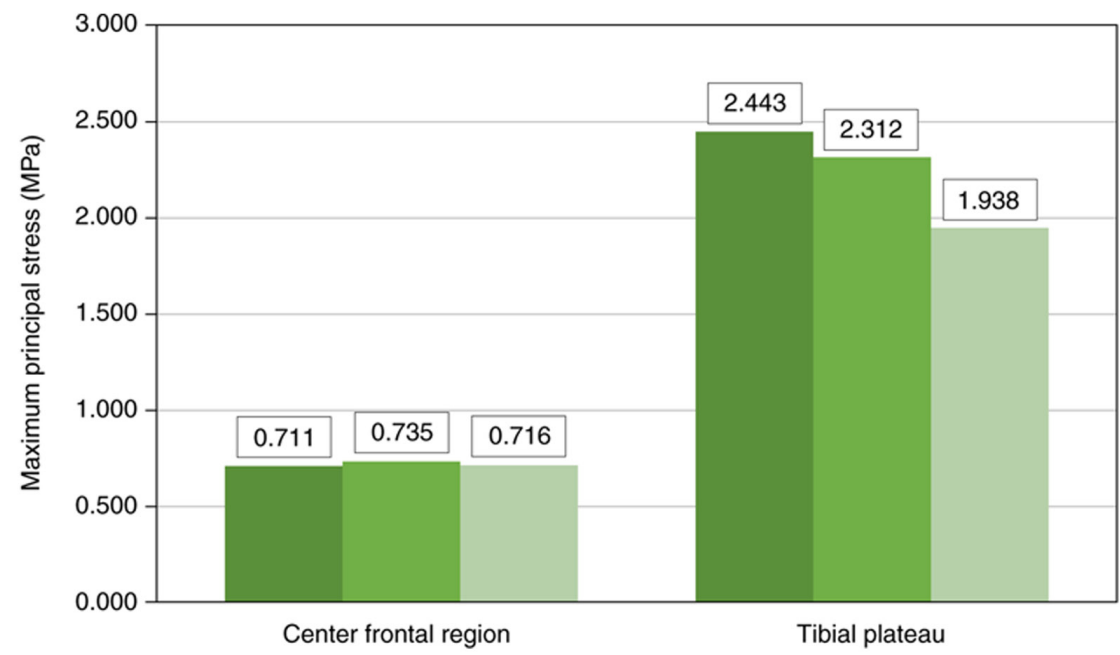

Single medial plating

Single lateral plating

Dual plating

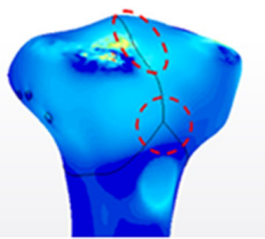

Figure 4. Maximum principal stress recorded at cortical bone level, in the vicinity of the fracture lines, in the center frontal and tibial plateau region.

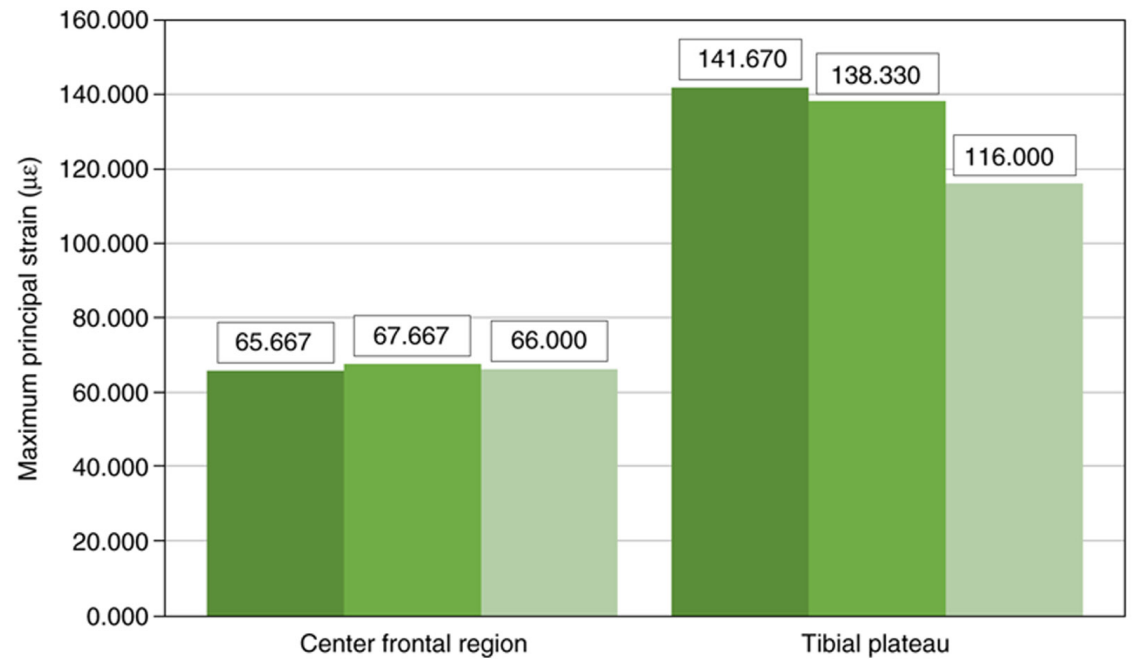

Single medial plating

Single lateral plating

Dual plating

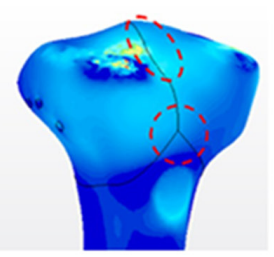

Figure 5. Maximum principal strain recorded at cortical bone level, in the vicinity of the fracture lines, in the center frontal and tibial plateau region.

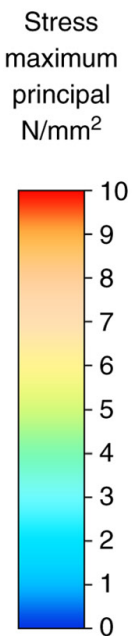

A

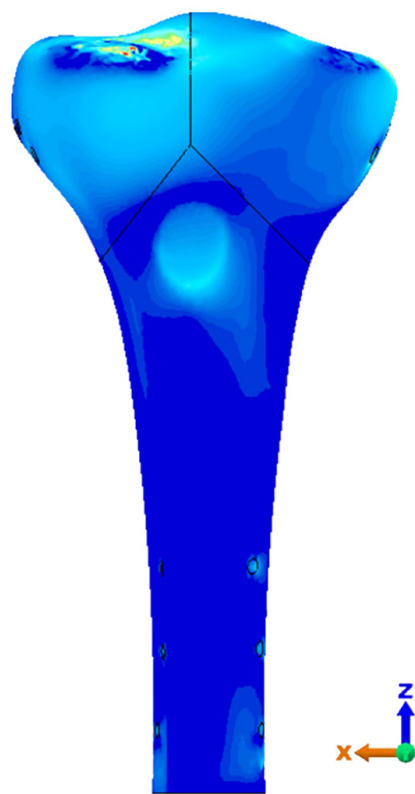

$\mathrm{B}$

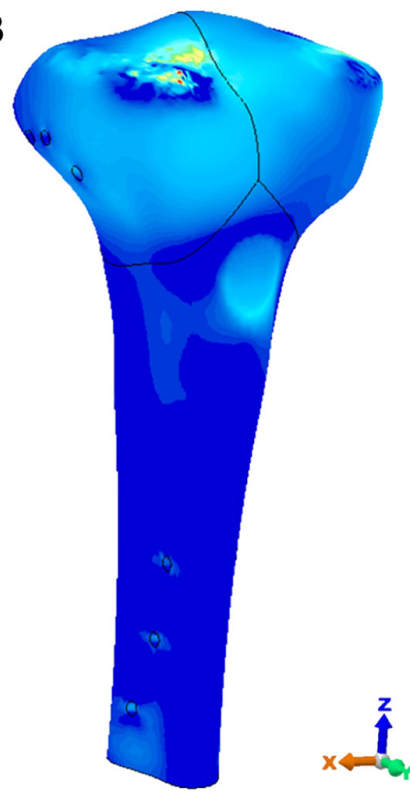

C

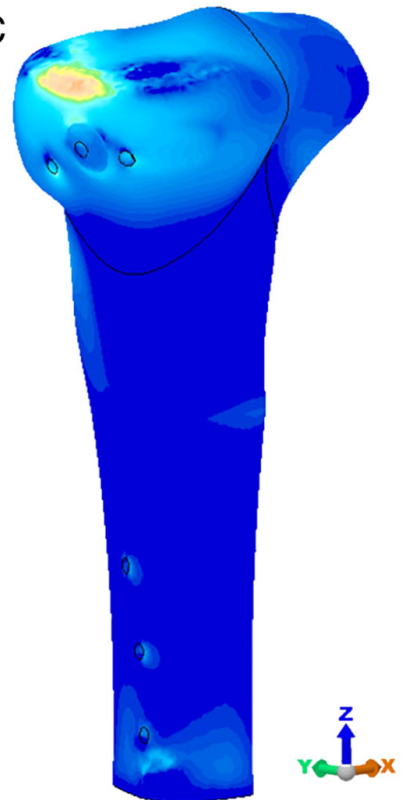

Figure 6. Distribution of the maximum principal stress for single medial plating. Descriptive (A) anterior, (B) antero-lateral, and (C) postero-medial view. 

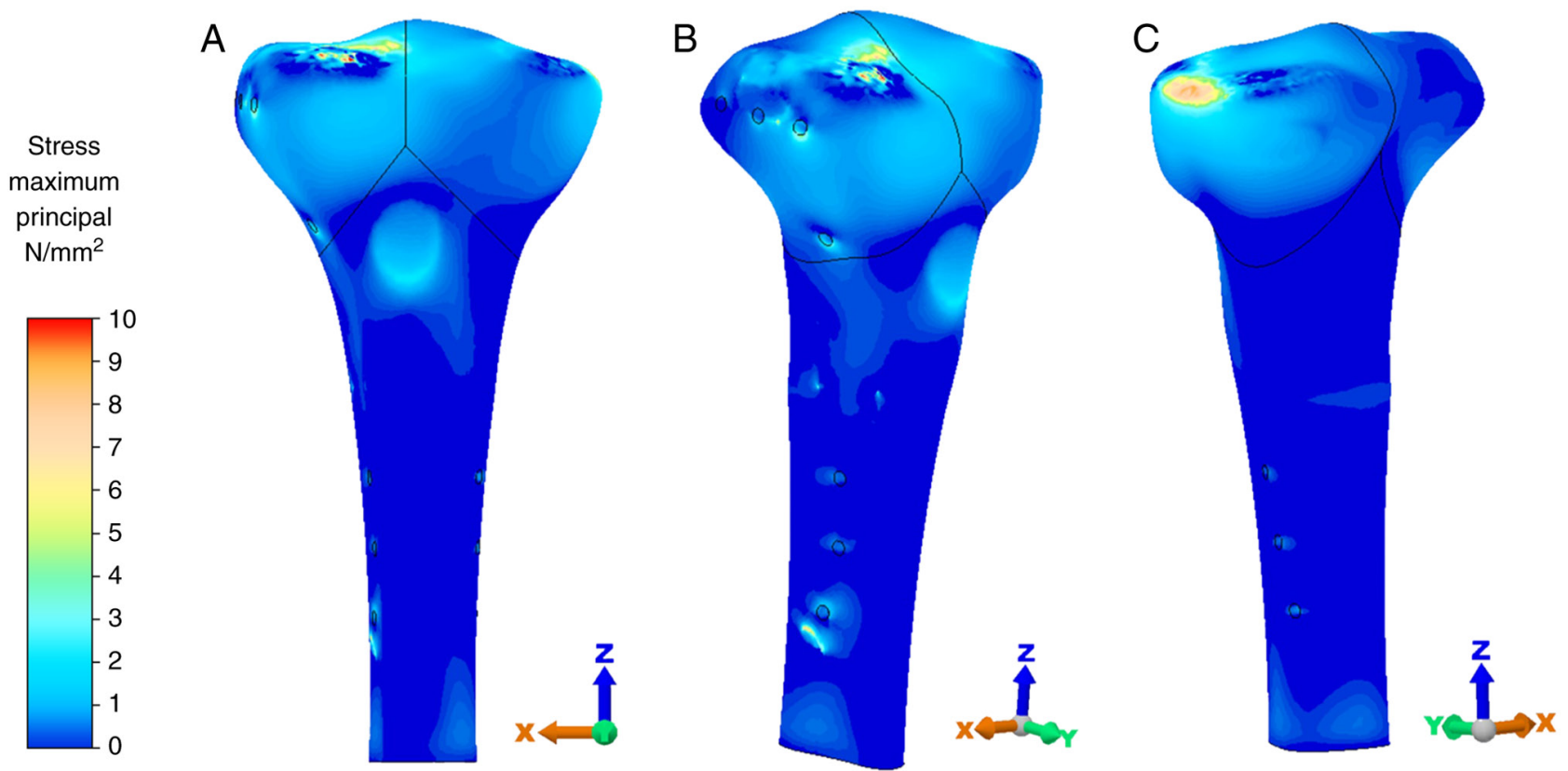

Figure 7. Distribution of the maximum principal stress for single lateral plating. Descriptive (A) anterior, (B) antero-lateral, and (C) postero-medial view.

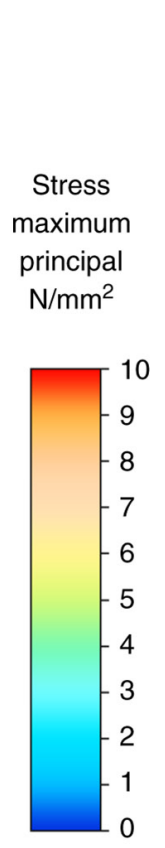

A

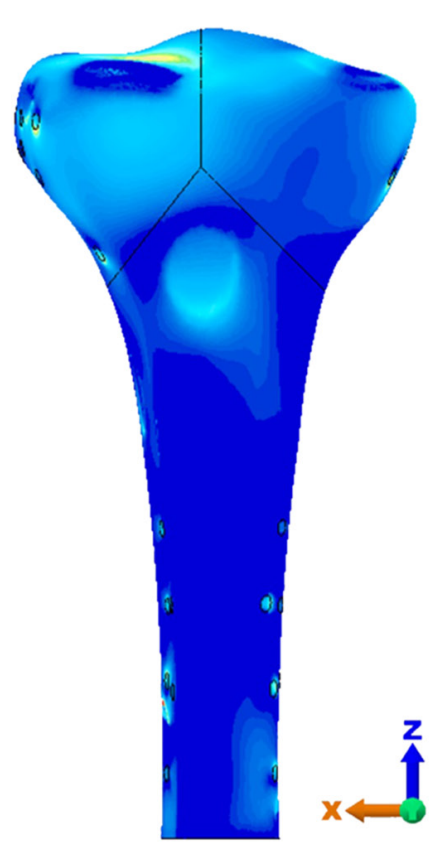

B

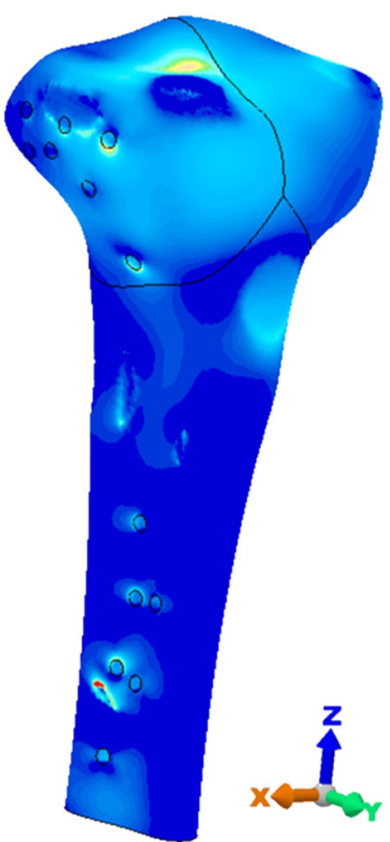

C

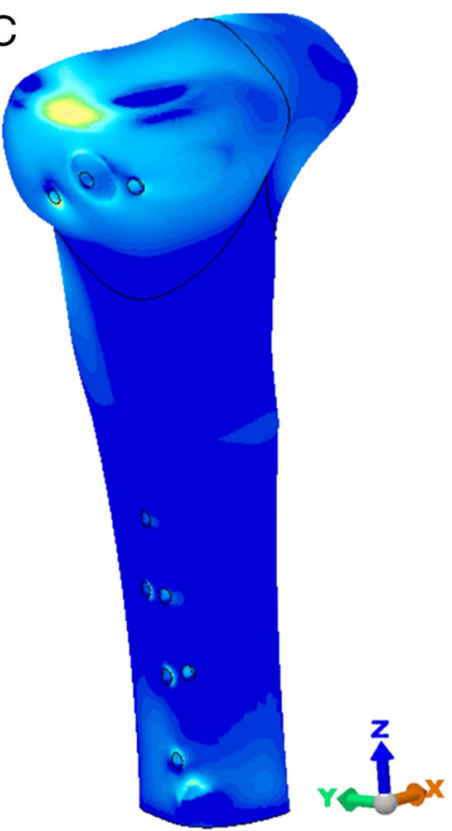

Figure 8. Distribution of the maximum principal stress for dual plating. Descriptive (A) anterior, (B) antero-lateral, and (C) postero-medial view.

fracture is also highlighted by the variety of technical solutions for reduction and stabilization. Normal means are open reduction and internal fixation in the bicondylar fractures of the tibial plateau $(4,35)$.

In the context of a lack of FEA studies addressing the C1.1 fracture type (AO-41) and the limitations of the FEA method, the results obtained in the present study need to be analyzed together with several aspects. The materials assigned to the 3D models were considered elastic linear. The values of the muscle PCSA used to calculate the force were obtained from cadaveric specimens and may be smaller than in vivo measured values in patients (22). Furthermore, the normalized EMG activity values were taken from a gait cycle of $1 \mathrm{~m} / \mathrm{sec}$ speed. Although smaller than the average walking speed, slow walking speed is approximately $0.66 \mathrm{~m} / \mathrm{sec}(32)$. A smaller walking speed may lead to smaller applied forces and thus to decreased stress and strain. Nevertheless, studies are required to determine the variation of muscle forces in a slow walking cycle, in the context of a reduced and stabilized bicondylar tibial plateau fracture. Concurrently, it is necessary to determine the variation of the GRF that occurs during a postoperative slow walking cycle, to obtain appropriate reference values. It is imperative that such studies be conducted on postoperative patients for the accuracy of data. 
Considering the limitations of this study, the results of the present study have shown that dual plating leads to smaller stress and strain values near the fracture lines in the tibial plateau area. However, values obtained for single lateral plating were close in range. Considering the complexity of the surgical approach for dual plating, single lateral plating may be a solution for good reduction with fewer surgical risks and complications. Plates with polyaxial stability allow for adaptation of the position of the screws to the fracture trajectory. This provides the means for appropriate fixation and stabilization through a single plate with lateral fixation.

The values of strain obtained in both areas are found in the minimum strain range. Although in the present study, it is considered that the bone is not loaded enough to achieve bone remodeling or homeostasis, it is notable that the stresses transmitted by the plates and screws should not cause associated trauma but should only stabilize and reduce the fracture to promote healing.

The present study can be further developed to explore forces that occur in other moments of a slow walking cycle to describe the complete loading of the fractured tibia. However, studies are required to determine the variation of muscle forces that occur in a slow walking cycle, in the context of a reduced and stabilized bicondylar fracture at the tibial plateau.

Further studies on the $\mathrm{C} 1.1$ fracture (AO-41) are required to analyze the complex issue of reducing and stabilizing such a fracture and to characterize the postoperative state while providing predictable parameters for an optimal result.

\section{Acknowledgements}

Not applicable.

\section{Funding}

No funding was received.

\section{Availability of data and materials}

All data analyzed during this study are included in this published article.

\section{Authors' contributions}

NF, FM and SABM conceived the study. NF, FM, SABM and PDS developed and designed the methodology. NF, FM, SABM, PDS, LS and BP performed formal data analysis. NF, FM, SABM, LS and BP performed curation and interpretation of data. All authors provided resources. All authors worked on the original draft and editing of the manuscript. NF, FM and SABM confirm the authenticity of all the raw data. All authors have read and agreed to the published version of the manuscript.

\section{Ethics approval and consent to participate}

Not applicable.

\section{Patient consent for publication}

Not applicable.

\section{Competing interests}

The authors declare that they have no competing interests.

\section{References}

1. Urruela AM, Davidovitch R, Karia R, Khurana S and Egol KA: Results following operative treatment of tibial plateau fractures. J Knee Surg 26: 161-165, 2013.

2. Rademakers MV, Kerkhoffs GM, Sierevelt IN, Raaymakers EL and Marti RK: Operative treatment of 109 tibial plateau fractures: Five- to 27-year follow-up results. J Orthop Trauma 21: 5-10, 2007.

3. Markhardt BK, Gross JM and Monu JUV: Schatzker classification of tibial plateau fractures: Use of CT and MR imaging improves assessment. Radiographics 29: 585-597, 2009.

4. Lee AK, Cooper SA and Collinge C: Bicondylar tibial plateau fractures: A critical analysis review. JBJS Rev 6: e4, 2018.

5. Meinberg EG, Agel J, Roberts CS, Karam MD and Kellam JF: Fracture and dislocation classification compendium-2018. J Orthop Trauma 32 (Suppl 1): S1-S170, 2018.

6. Sîrbu PD, Friedl W, Carata E, Petreus T, Poroch V, Botez P and Stratulat S: Are the plates with polyaxial stability (pas) the ideal treatment in complex periarticualar fractures? Bul Inst Polit Iaşi Tomul LVII (LXI) Fasc. 4: 212-19, 2011.

7. Barei DP, Nork SE, Mills WJ, Coles CP, Henley MB and Benirschke SK: Functional outcomes of severe bicondylar tibial plateau fractures treated with dual incisions and medial and lateral plates. J Bone Joint Surg Am 88: 1713-1721, 2006.

8. Ali AM, Burton M, Hashmi M and Saleh M: Treatment of displaced bicondylar tibial plateau fractures (OTA-41C2\&3) in patients older than 60 years of age. J Orthop Trauma 17: 346-352, 2003.

9. Schwartsman R, Brinker MR, Beaver R and Cox DD: Patient self-assessment of tibial plateau fractures in 40 older adults. Am J Orthop (Belle Mead NJ) 27: 512-519, 1998.

10. Morris BJ, Unger RZ, Archer KR, Mathis SL, Perdue AM and Obremskey WT: Risk factors of infection after ORIF of bicondylar tibial plateau fractures. J Orthop Trauma 27: e196-e200, 2013.

11. Colman M, Wright A, Gruen G, Siska P, Pape HC and Tarkin I: Prolonged operative time increases infection rate in tibial plateau fractures. Injury 44: 249-252, 2013.

12. Rasmussen PS: Tibial condylar fractures. Impairment of knee joint stability as an indication for surgical treatment. J Bone Joint Surg Am 55: 1331-1350, 1973.

13. Merchant TC and Dietz FR: Long-term follow-up after fractures of the tibial and fibular shafts. J Bone Joint Surg Am 71: 599-606, 1989.

14. van den Munckhof S and Zadpoor AA: How accurately can we predict the fracture load of the proximal femur using finite element models?. Clin Biomech (Bristol, Avon) 29: 373-380, 2014.

15. Vulovic A, Šušteršič T and Filipovic N: Finite element analysis of femoral implant under static load. 2017 IEEE 17th International Conference on Bioinformatics and Bioengineering (BIBE), pp.559-562, 2017. doi: 10.1109/BIBE.2017.00012.

16. Carrera I, Gelber PE, Chary G, Gonzalez-Ballester MA, Monllau JC and Noailly J: Fixation of a split fracture of the lateral tibial plateau with a locking screw plate instead of cannulated screws would allow early weight bearing: A computational exploration. Int Orthop 40: 2163-2169, 2016.

17. Luo CA, Hua SY, Lin SC, Chen CM and Tseng CS: Stress and stability comparison between different systems for high tibial osteotomies. BMC Musculoskelet Disord 14: 110, 2013.

18. Peña E, Calvo B, Martínez MA, Palanca D and Doblaré M: Finite element analysis of the effect of meniscal tears and meniscectomies on human knee biomechanics. Clin Biomech (Bristol, Avon) 20: 498-507, 2005.

19. Diffo Kaze A, Maas S, Kedziora S, Belsey J, Haupert A, Wolf C, Hoffmann A and Pape D: Numerical comparative study of five currently used implants for high tibial osteotomy: Realistic loading including muscle forces versus simplified experimental loading. J Exp Orthop 5: 28, 2018.

20. Arnold EM, Hamner SR, Seth A, Millard M and Delp SL: How muscle fiber lengths and velocities affect muscle force generation as humans walk and run at different speeds. J Exp Biol 216: 2150-2160, 2013 
21. Enoka RM (ed): Neuromechanics of human movement. Human Kinetics. 4th edition. Champaign, IL, p 370, 2008.

22. Ward SR, Eng CM, Smallwood LH and Lieber RL: Are current measurements of lower extremity muscle architecture accurate? Clin Orthop Relat Res 467: 1074-1082, 2009.

23. Adouni M and Shirazi-Adl A: Evaluation of knee joint muscle forces and tissue stresses-strains during gait in severe OA versus normal subjects. J Orthop Res 32: 69-78, 2014

24. Mesfar W and Shirazi-Adl A: Biomechanics of the knee joint in flexion under various quadriceps forces. Knee 12: 424-434, 2005.

25. Mesfar W and Shirazi-Adl A: Knee joint mechanics under quadriceps-hamstrings muscle forces are influenced by tibial restraint. Clin Biomech (Bristol, Avon) 21: 841-848, 2006.

26. Aalbersberg S, Kingma I, Ronsky JL, Frayne R and van Dieen JH: Orientation of tendons in vivo with active and passive knee muscles. J Biomech 38: 1780-1788, 2005.

27. Hillman SK. In: Essentials of Interactive Functional Anatomy Cdr Edition. Primal Pictures (ed). London, UK, 2003.

28. Frost HM: Bone 'mass' and the 'mechanostat': A proposal. Anat Rec 219: 1-9, 1987.
29. Huiskes R, Weinans H, Grootenboer HJ, Dalstra M, Fudala B and Slooff TJ: Adaptive bone-remodeling theory applied to prosthetic-design analysis. J Biomech 20: 1135-1150, 1987.

30. Mullender MG and Huiskes R: Proposal for the regulatory mechanism of Wolff's law. J Orthop Res 13: 503-512, 1995.

31. Frost HM: A 2003 update of bone physiology and Wolf's law for clinicians. Angle Orthod 74: 3-15, 2004.

32. Perry J and Bumfield JM: Gait analysis: Normal and pathological function. Slack, Thorofare NJ, pp432-454, 1992.

33. Samsami S, Herrmann S, Pätzold R, Winkler M and Augat P: Finite element analysis of $\mathrm{Bi}$-condylar Tibial Plateau fractures to assess the effect of coronal splits. Med Eng Phys 84: 84-95, 2020.

34. Kumar G, Peterson N and Narayan B: Bicondylar tibial fractures: Internal or external fixation? Indian J Orthop 45: 116-124, 2011.

35. Johnson EE, Timon S and Osuji C: Surgical technique: Tscherne-Johnson extensile approach for tibial plateau fractures. Clin Orthop Relat Res 471: 2760-2767, 2013.

(i) 9 This work is licensed under a Creative Commons (c) ${ }_{\mathrm{EY}}$ NG NO Attribution-NonCommercial-NoDerivatives 4.0 International (CC BY-NC-ND 4.0) License. 